\title{
Alternatives for mobile operators in the competitive 3G and beyond business
}

\author{
Jarmo Harno • Dimitris Katsianis • Timo Smura • \\ Thor Gunnar Eskedal • Rima Venturin . \\ Olli Pekka Pohjola $\cdot$ K.R. Renjish Kumar • \\ Dimitris Varoutas
}

Published online: 23 April 2009

(C) Springer Science+Business Media, LLC 2009

\begin{abstract}
The importance of analyzing different business models and technologies in the mobile industry has become more crucial for the investment policy of the telecom operators. This paper aims to cover some of the most interesting business alternatives in providing the new $3 \mathrm{G}$ and beyond services including cases where the operator already has an existing second-generation cellular network and perhaps even a license for the $3 \mathrm{G}$ UMTS network, and cases where the operator does not have any existing network. Three cases for incumbents and new entrants are foreseen, leaving alternatives for new competing $3 \mathrm{G}$ technology deployment or acting as a mobile virtual network operator (MVNO) without owning any radio infrastructure. A techno-economic approach has been used to identify business opportunities and quantify the potential profitability of different kind of business players. The scenarios have been analyzed in the Western European context by different country groups that are not exactly representative of any defined country, but rather share typical demographic characteristics.
\end{abstract}

J. Harno (凶)

Nokia Siemens Networks, Linnoitustie 6, 02600 Espoo, Finland

e-mail: jarmo.harno@gmail.com

D. Katsianis · D. Varoutas

University of Athens, Athens, Greece

T. Smura $\cdot$ K.R.R. Kumar

Helsinki University of Technology, Helsinki, Finland

T.G. Eskedal $\cdot$ R. Venturin

Telenor, Fornebu, Norway

O.P. Pohjola

Nokia, Espoo, Finland
Keywords Mobile telecommunication · Network and service rollout $\cdot$ Business models $\cdot$ MVNO $\cdot 3 \mathrm{G}$

\section{Introduction}

Mobile business has become one of the drivers of the world economy during the last 10 years. Implications of new technologies, user needs, emerging business models, market and demographic conditions and regulatory aspects have to be understood, as creating a successful investment strategy for a network, service or virtual operator. The winning schemes and the financial margins for each business approach have to be discovered.

Offering rich broadband services in conjunction with the traditional mobile voice services seems to be the next step for most of the European network and service operators. Network operators are extending their capacity for wideband/broadband applications, whereas service operators promote new services to attract customers and increase revenues. 3G mobile technologies have opened up new possibilities in providing advanced value-added data and content services, such as rich video and audio, games, location services and $\mathrm{m}$-commerce. Service related aspects have to be combined with different technologies, and all the possible business plans, with deferent partnering alternatives, should be investigated by the players, making the beyond 3G business extremely complicated.

Techno-economic analysis of telecommunication systems and services, combining the economical and business aspects with a comprehensive technical parameters modeling, has not been widely published [1-3]. Handling of business models and earning logics has to be combined with market forecasts, willingness to pay, and cost modeling of 
both operational and capital expenditures in a right granularity to gain balanced results.

In this paper, a representative set of possible business scenarios have been selected. These include cases for incumbents and new entrants, those having a UMTS license and those lacking it-leaving a choice between using an alternative technology or acting as a Mobile Virtual Network Operator (MVNO) without own radio infrastructure. These scenarios will be described in the next chapters, with the aim to highlight the potential business profitability by utilizing various types of technology and business models. A technoeconomic approach has been used to identify business opportunities and quantify the potential profitability of different kind of business players. With the utilized scenario approach we analyze three alternatives to enter the beyond $3 \mathrm{G}$ mobile business, as the possibilities are quite different depending on the background and assets in the telecom business, and on the investment potential and risk aversion of the company.

The presented results are based on the work within EUREKA Celtic project ECOSYS. For more details, please see the reference [4].

\section{Business scenarios selection}

In this paper, three scenarios are introduced to cover some of the most interesting business alternatives in providing the new $3 \mathrm{G}$ and beyond services. The opportunities and strategies differ between operators that already have an existing second-generation cellular network and possibly a license for the 3G UMTS network, and operators that do not have any existing network.

Scenario 1 (2G incumbent operator with or without UMTS license) analyses the incumbent player, i.e. one who has an existing $2 \mathrm{G}$ network, and wants to deploy its own $3 \mathrm{G}$ network. This study setting compares, two alternatives: UMTS deployment (with license), and a new competing $3 \mathrm{G}$ technology deployment. As we are here looking at incumbent players, we normally have clear connection between the Service Operator and the Network Operator sides of the business. So in this scenario we have currently only one Service Operator and one Network Operator linked together. Even as such, however, this separation gives interesting insight to the economical dynamics of these entities. There is available techno-economic research handling the $3 \mathrm{G}$ competition on a monolithic operator framework, e.g. [5-7] and [8], but they are not analyzing the service and network sides of the business separately.

The competing $3 \mathrm{G}$ technology here was in the early study period loosely defined as "OFDM", the characteristics of which include full IP compatibility throughout the network, and an effective OFDM radio frequency utilization. Later, as the competition revealed WiMAX to be the most prominent challenger of the cellular based 3G technologies, the analysis was completed with the technical and economical parameters relating to Mobile WiMAX (IEEE 802.16e). Within all alternatives, full GPRS coverage is supposed to be already built, and it is possible to utilize also EDGE technology as a fast upgrade for new services. As all the investigated technologies have different performance characteristics, which on their half affect the user behavior in the service take-up, the modeling of these characteristics is of crucial importance.

The first scenario tries to find answers to questions like: Is it possible in the Western European context to compete UMTS with some other technology, if no license for UMTS frequencies is possessed? How the business situation differs for the Service Operator compared to Network Operator? Is an intermediate EDGE deployment paying back in the end results? Does the HSDPA upgrade increase profitability or not?

Scenario 2 (2G and 3G Service Provider/MVNO) analyzes the new entrant case, where there are no new licenses available for GSM/UMTS networks. Many firms, working in the telecom sector or not, have expressed their interest to enter the market through the networks operation or the service provision channel. For those, who have been left without license, a new channel to enter the market is the MVNO channel or the service-provisioning channel. This scenario is important for comparing the investment levels, cost structures, and revenue streams between the SP and MVNO scenarios as well as analyzing the key differences between these two models in terms of business profitability.

Scenario 3 (CDMA450 Business Case) analyzes the new entrant case, where there is possibility to get a license to build a network utilizing the $450 \mathrm{MHz}$ frequency band. CDMA450, based on the CDMA 2000 technology, has attracted keen interest in the industry. One of the initial drivers has been the opportunity to reuse the $450 \mathrm{MHz}$ spectrum from the exiting NMT450 analogue cellular systems for a new digital radio technology. In addition to the wide coverage capabilities of the $450 \mathrm{MHz}$ spectrum due to the low frequency, the CDMA450 system enables building a 3G like mobile network with enhanced service capabilities compared to 2G. The scenario thus describes the case of a Greenfield CDMA 450 operator entering the market concentrating to the sparsely populated areas.

\section{Assumptions}

A study period of eight years and a discount factor of $15 \%$ are used in the analysis for all scenarios. 


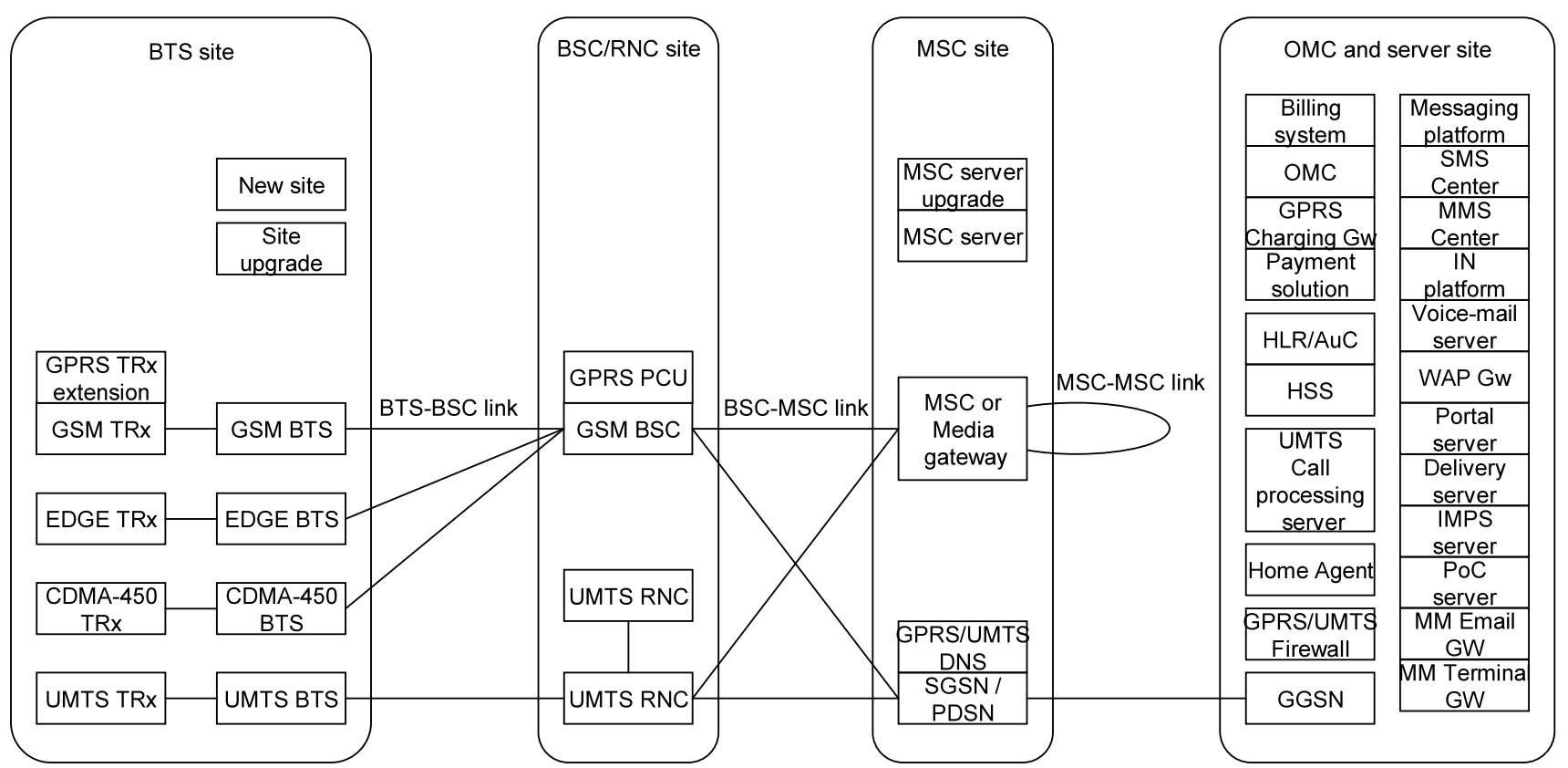

Fig. 1 Mobile network architecture

\subsection{Country types}

For all the cases two generic country types are modeled taking into account geographic characteristics: The country types are according to the population.

"Large" = Western European country like France, Germany, Italy, or UK

"Nordic" = Northern European country like Denmark, Finland, Norway or Sweden

This separation to "Nordic" and "Large" countries was done because investment cost and revenues are very much linked to the population and the potential customer base. The country surface area has been supposed to be $370000 \mathrm{~km}^{2}$ for "Large" country (calculated average from France, Germany, Italy and UK), and $330000 \mathrm{~km}^{2}$ for "Nordic" country (median from Denmark, Finland, Norway and Sweden, leading to about the size of Finland and Norway). Also the total populations were chosen accordingly. The license fees for different countries are not included in the calculations, but can be considered when looking for the final results of each country. The country demographics are presented in Table 1 below. The overall size of the surface area isn't the sum of all the sub-areas because certain areas (e.g. lakes, mountain tops etc.) are not taken into account. The user density figures refer to the amount of users in each area type during the busy hour specific to that area type. These figures are used for traffic division into areas, used in the capacity build-out calculations. The busy hour users in all areas sum up to more than the total population.
3.2 Markets and services

Customer segments Customer segmentation is one of the key assumptions made for estimating the market demand and service usage in our model. The subscribers are divided into four exclusive customer segments, and the percentage split between those is assumed to be as follows:

- Business subscriptions: $20 \%$

- Youth subscriptions: $20 \%$

- Advanced subscriptions: $20 \%$

- Basic subscriptions: $40 \%$

Service characteristics and pricing Assumptions regarding service classification and pricing are presented in Table 2 . The service prices are assumed to be, on average, same for all segments.

\subsection{Network architecture}

Figure 1 shows the generic network architecture used in the modeling, and the mapping of different network elements to certain sites in the architecture.

In our modeling, we consider four different kinds of equipment sites to exist. The BTS sites are housing the radio base station equipment, radio transceivers (TRx), and related mast, cabling, and antenna equipment. The BSC/RNC sites house the base station controllers, whereas the MSC sites are housing the switching equipment. Centralized OMC sites are housing all the support systems and servers. 
Table 1 Population covered in Large and Nordic country examples

\begin{tabular}{llll}
\hline Country type & Large & Nordic & Description \\
\hline Area size & 370,000 & 330,000 & Size of surface area of the country $\left(\mathrm{km}^{2}\right)$ \\
Area dense & 185 & 17 & Size of dense urban area $\left(\mathrm{km}^{2}\right)$ \\
Area urban & 2,960 & 264 & Size of urban area $\left(\mathrm{km}^{2}\right)$ \\
Area suburban & 37,000 & 3,300 & Size of suburban area $\left(\mathrm{km}^{2}\right)$ \\
Area rural & 303,400 & 264,000 & Size of rural area $\left(\mathrm{km}^{2}\right)$ \\
Users dense & 50,000 & 50,000 & Number of users in dense urban area per km ${ }^{2}($ during busy hour) \\
Users urban & 4,000 & 4,000 & Number of users in urban area per km ${ }^{2}($ during busy hour) \\
Users suburban & 1,000 & 1,000 & Number of users in suburban area per km ${ }^{2}($ during busy hour) \\
Users rural & 40 & 3 & Number of users in rural area per km ${ }^{2}(\mathrm{during}$ busy hour $)$ \\
Total Population & $65,000,000$ & $5,500,000$ & Total population \\
\hline
\end{tabular}

Table 2 Service classification and pricing

\begin{tabular}{|c|c|c|c|c|}
\hline Service & Description & Price unit & Price in 2005 & Ann. price reduct. \\
\hline Subscription & SIM card & $€ /$ month & 2.00 & $0 \%$ \\
\hline Voice & Make and receive calls & $€ /$ min & 0.08 & $15 \%$ \\
\hline Video call & Make and receive calls & $€ /$ min & 0.16 & $15 \%$ \\
\hline Push-to-talk over cellular & Make and receive calls & $€ / \mathrm{min}$ & 0.05 & $10 \%$ \\
\hline SMS & Send and receive messages & $€ / \mathrm{msg}$ & 0.08 & $5 \%$ \\
\hline MMS & Send and receive messages & $€ / \mathrm{msg}$ & 0.24 & $10 \%$ \\
\hline Email & Retrieve and send Emails & $€ / \mathrm{MB}$ & 0.80 & $20 \%$ \\
\hline Transactions & Ringtones, images, payments & $€ /$ transact. & 0.50 & $10 \%$ \\
\hline Downloads & E.g. music files and games & $€ /$ transact. & 1.00 & $20 \%$ \\
\hline Browsing & Browse to web sites and content & $€ / \mathrm{MB}$ & 0.80 & $20 \%$ \\
\hline Streaming & Audio streaming & $€ / \mathrm{MB}$ & 0.80 & $20 \%$ \\
\hline Other data & Business data etc. & $€ / \mathrm{MB}$ & 0.80 & $20 \%$ \\
\hline
\end{tabular}

Network elements Table 3 shows assumptions regarding the cost and capacity characteristics of some of the key radio network elements. Only radio network elements are presented here as they comprise about two thirds of the total network investments. For control, core, operation and support, and service related elements and prices, refer to the ECOSYS deliverables [1]. For many elements, like base stations, the anticipated annual price reduction is about $15 \%$ in the beginning of the study period (price curve with several parameters applied; for the Cost Evolution Model refer to [8] and [11]).

Network dimensioning Network dimensioning aims at calculating the optimal number of network elements (including nodes and links) that fulfills the capacity, coverage, and quality of service demands of the service area at minimal total costs (OPEX + CAPEX).

The network dimensioning in the business cases is modeled according to the following logic:
1. Traffic demands in different area types are calculated based on the service usage forecasts.

2. The number of radio base station sites and transceivers is calculated for each area type based on the cell range and capacity assumptions.

3. The number of core network elements like BSC/RNCs and MSCs, SGSNs, GGSNs is calculated from the base station amount, generated traffic load and subscriber/user amount based on the network element capacities.

4. The number of backhaul and core transmission links (BTS-BSC, BSC-MSC, MSC-MSC) is calculated based on network architecture, generated traffic, and available link capacities. Transmission network is not built by the operator themselves, but leased, and the costs are thus included in the operational expenses.

5. The number of OMC-related and value-added service elements is calculated based on capacity figures relating to number of transactions, service requests, messages, and users. In some cases, just one element is needed per operator. 
Table 3 Network element characteristics

\begin{tabular}{lll}
\hline Component & Reference price 2005 & Capacity \\
\hline EDGE BTS Site and Installation & 30000 (no price reduction) & Upgrade to existing GSM site, no active equipment \\
EDGE BTS (update) & 24000 & 3 sectors + 3 TRX install., max 6 TRX per sector, max 18 TRX per BTS \\
EDGE additional TRX & 5700 & Max. 256 kbps \\
UMTS BTS Site Installation & 35000 (no price reduction) & Upgrade to existing GSM site, no active equipment \\
UMTS BS & 34000 & 3 sectors $\times$ 2 bands, max 6 TRX per sector, max 18 TRX per BS \\
UMTS TRX Extension & 6600 & Max. 800 kbps (real av. throughput) \\
UMTS BS with HSPA & 46000 & 3 sectors $\times 2$ carriers \\
Mobile WiMAX BS & 30000 (year 2006 price estim.) & 10 MHz carrier/3.5 GHz spectrum \\
3G_SiteBuildOut & 110000 (no price red.) & Price per new site \\
CDMA Base station upfront & 26000 & Including a 6-sector space, multiplexer and backhaul interface, \\
powering and software license. \\
CDMA450 site (new site) & 115000 & New site, no active equipment \\
CDMA450 site (co-sited) & 35000 & New site, no active equipment \\
CDMA450 TRx & 2900 & Max 3 Mb/s \\
GSM BSC & 350000 & Max. 300 TRX per BSC \\
UMTS RNC & 1300000 & Max. 100 UMTS BS per RNC, Max. 250 Mbps \\
\hline
\end{tabular}

Table 4 Radio network dimensioning parameters

\begin{tabular}{|c|c|c|c|c|}
\hline Technology & $\begin{array}{l}\text { Frequency band } \\
(\mathrm{MHz})\end{array}$ & Channel bandwidth & $\begin{array}{l}\text { Channel throughput } \\
\text { (average, DL) }\end{array}$ & $\begin{array}{l}\text { Cell range }{ }^{\mathrm{a}}(\mathrm{km})(\text { Dense/Urban/ } \\
\text { Suburb./Rural) }\end{array}$ \\
\hline GSM & $900 / 1800$ & $200 \mathrm{kHz}$ & 6.4 calls & $0.73 / 2.51 / 3.21 / 6.36$ \\
\hline GPRS & $900 / 1800$ & $200 \mathrm{kHz}$ & $70.4 \mathrm{kbps}$ & $0.73 / 2.51 / 3.21 / 6.36$ \\
\hline EDGE & $900 / 1800$ & $200 \mathrm{kHz}$ & $256 \mathrm{kbps}$ & $0.73 / 2.51 / 3.21 / 6.36$ \\
\hline WCDMA & $1900 / 2100$ & $5 \mathrm{MHz}$ ( 2 channels per sector) & 96 calls/800 kbps & $0.57 / 0.89 / 2.11 / 6.36$ \\
\hline HSPA & $1900 / 2100$ & $5 \mathrm{MHz}$ (2 channels per sector) & $4 \mathrm{Mbps}^{\mathrm{b}}$ & 0.57/0.89/2.11/6.36 (not implemented) \\
\hline WiMAX & 3400 & $10 \mathrm{MHz}$ & $10 \mathrm{Mbps}^{\mathrm{b}}$ & 0.40/0.60/1.10 (not implem.)/3.00 (not impl.) \\
\hline CDMA450 & 450 & $1.25 \mathrm{MHz}$ & $700 \mathrm{kbps}$ & $1.5 / 2.5 / 5 / 15$ \\
\hline
\end{tabular}

${ }^{a}$ Three sector cells, indoor coverage probability $80 \%$, also outdoor coverage might be relevant in certain later described cases

${ }^{b}$ Optimistic in relation to current simulations against realistic conditions, takes into account the future development; at least 2-Rx terminals or MIMO assumed

For radio network dimensioning, the required assumptions include both coverage and capacity related parameters, as shown in Table 4.

\subsection{Operational expenditures}

The following generic breakdown is used to distribute the relative OPEX costs according to the available information:

Group A: Network related elements

- Maintenance of equipment and components

- Equipment and software licenses, outsourcing

- Network operation and maintenance (incl. OSS)

- Planning and optimization

- Rental of physical network resources, e.g. leased lines

- Site rental and electricity costs
- Yearly cost of radio spectrum licenses

Group B: Marketing and sales related elements

- Sales and marketing

- Customer acquisition

- Handset subsidies

Group C: Customer service related elements

- Customer activation and provisioning

- Call center

- Interactive Voice Response (IVR) system

- Customer care

- Billing (BSS)

- Credit losses 
Group D: IT, support and service development related elements

- Service management

- New service development

- Business IT (like SAP)

- Payroll systems

- Logistics and inventory

- Human resources management

- Management support

- End-user support

- Reporting for the regulator

- Third parties/consulting

- Content related

Group E: Interconnection and roaming costs

- Roaming

- Interconnection (e.g. termination fees)

It should be noted that the "cost of goods sold" is not included in this breakdown, although many operators act also as handset resellers. Neither are the related revenues counted in the business cases, but the handset subsidies costs are tracked separately and included here in the sales and marketing costs. For more information about the presented grouping, please see the ECOSYS Deliverable 6 "OPEX models" [4].

Our estimation of monthly OPEX costs of 13-39 $€$ per subscriber can be further divided into grouping presented above, based on the knowledge and history data we have on the GSM operators. Here again we perceive much variance between different kinds of operators. Diverse competition strategies are available that affect immediately one or more of the OPEX groups: high or low network quality, big or small marketing investments, good or moderate customer service, etc.

For reference, the estimated W-European division of total network and service operator OPEX in the case studies is as follows:
- Network related elements $20 \%$

- Marketing and sales related elements $26 \%$

- Customer service related elements $8 \%$

- IT, support and service development $11 \%$

- Interconnection and roaming costs $35 \%$

Leased line rental Costs relating to the base station backhaul and transport network connecting the BSC sites and core sites are modeled as leased lines and thus included into the operational expenditures. The required number of base station sites, BSC/RNC sites, and core network elements in each area type is calculated according to the principles described in the Network dimensioning section. The assumed number of MSC sites and their interconnection links is 15 nodes and 23 links (providing redundant paths).

The number of leased lines between base station sites and RNC/BSC sites, as well as between RNC/BSC sites and MSC sites is calculated based on the traffic amounts. The required leased line lengths are calculated based on the assumptions shown in Table 5.

When the exact number of transmission links and their lengths (node distances) are known for each year, the related leased line costs (OPEX) are calculated according to Table 6.

It should be noted that the leased line prices in different countries might vary substantially.

\section{Scenario modeling, results and discussion}

\section{1 $2 \mathrm{G}$ incumbent operator with or without UMTS license case}

This scenario analyses the incumbent player, i.e. one who has an existing $2 \mathrm{G}$ network, and wants to deploy its own $3 \mathrm{G}$ network to survive in the new $3 \mathrm{G}$ and beyond service competition. This study setting includes, and compares, two
Table 5 Geographical distances between key network components

Table 6 Leased line tariff assumptions

\begin{tabular}{lllll}
\hline Distances $(\mathrm{km})$ & Dense urban & Urban & Suburban & Rural \\
\hline BS/BTS-RNC/BSC & 2 & 10 & 20 & 30 \\
RNC/BSC-MSC & 10 & 20 & 35 & 50 \\
MSC-MSC & $=2 * \sqrt{\frac{\text { CountryArea }\left(\mathrm{km}^{2}\right)}{\pi * \text { NumberOfMSCs}}}=177 \mathrm{~km}$ & & \\
\hline
\end{tabular}

\begin{tabular}{lll}
\hline Capacity & Basic price per line/year (2005) & Additional price per km/year (2005) \\
\hline $2 \mathrm{Mbit} / \mathrm{s}(\mathrm{BS} / \mathrm{BTS}-\mathrm{RNC} / \mathrm{BSC})$ & $5400 €$ & $486 €($ Large $)$ \\
& & $240 €$ (Nordic) \\
$155 \mathrm{Mbit} / \mathrm{s}(\mathrm{RNC} / \mathrm{BSC}-\mathrm{MSC})$ & $16913 €$ & $1920 €$ \\
Up to $10 \mathrm{Gbit} / \mathrm{s}$ & - & $3144 €$ \\
\hline
\end{tabular}


alternatives: UMTS deployment (with license), and a new competing $3 \mathrm{G}$ technology deployment. In both cases, an initial EDGE deployment is considered. For the UMTS case, also the potential savings through inclusion of HSDPA upgrade have been studied. For this scenario, only the "Large" country type has been analyzed.

This analysis approach is unique in published literature as linking three models dynamically together; namely the Network Operator cost modeling, the Service Operator service provisioning, revenue and operational expenditure modeling, and the end-user benefit and behavior modeling, all relating to the emerging advanced mobile telecommunication business and technologies.

\subsubsection{Technology alternatives investigated}

As an evolution path for GSM and GPRS technologies, EDGE, UMTS and HSDPA technologies are modeled. Mobile WiMAX technology has been modeled as representing an alternative technology approach for an operator without UMTS license. The technical and cost parameters of each technology have been presented in the previous chapter.

Worse availability and choice of the Mobile WiMAX handsets is seen in the lower service take-up figures in the beginning. As the Mobile WiMAX technology has been deployed in the higher bands, it has smaller site coverage area than UMTS. This has cost effects especially in the rural areas, where the capacity need per surface area is low. For these reasons Mobile WiMAX has been deployed only in the urban areas.

Although there are already several business case analyses for the fixed WiMAX, no comprehensive quantitative analyses, except some commercial analyst reports, are available on Mobile WiMAX. An extensive list of references on WiMAX technology is available in WiMAX Forum Internet pages [9], and on UMTS and HSDPA in Global mobile Suppliers Association (GSA) Internet pages [10].

The WiMAX, UMTS and HSDPA parameters presented in the preceding Assumptions chapter are based on real environment and normal usage conditions simulation results. Many earlier studies base on pre-implementation theoretical parameters.

\subsubsection{Rollout schemes and related investments}

The study period starts from year 2006 (first calculated investments) continuing until year 2013. In the beginning the Network Operator has the GSM capacity built up to support the traffic level at the year 2006. Also the initial quite low data traffic is supported by the existing GPRS capability. After that point, the needed extra GSM/GPRS capacity is rolled out and calculated in the model. If the EDGE capability update is decided to be rolled out, it takes place in the year 2006.
For the UMTS there are regulatory rollout requirements, which differ country by country, but we have used generic schedules. UMTS rollout starts in the year 2006, and the service is provided from the beginning of the year 2007. The deployment starts at the same time in all area types, but takes one year to cover the Dense area, two years for the Urban, three years for the Suburban, and 7 years to cover the whole rural area.

The rollout of the base stations (BS) is based on the cell ranges given in Table 4; three pentagon cells (sectors) are modeled for each BS, so that the BS coverage area is approximated to be $1.95 R^{2}$, where $R=$ "Cell range" in the Table 4 . Other equipments are counted accordingly, either based on BS amount, or the required capacity. Most significant elements' capacities and historical price data are presented in the Table 3. A cost evolution model utilizing learning curve expression with several parameters has been applied; for the formulas refer to [8] and [11]. For elements like base stations, the anticipated annual price reduction is about $15 \%$ in the beginning of the study period. After the BS coverage has been built out, the needed additional BS/TRX capacity is rolled out in the previous calendar year of the foreseen traffic amount; the capacities (throughputs) of the different radio technology BSs are included in the Table 4.

The Mobile WiMAX rollout is considered later than in the UMTS case, starting in the year 2007, so that the service provisioning can start in the beginning of the year 2008 . The rollout schedule has the same pace as with UMTS, but without the suburban and rural rollout. The development of population coverage for different technologies is presented in the following figure. In addition, the potential traffic from the terminals using the most advanced technologies has been presented.

An extensive list of references on cost analysis of the wireless networks can be found in [12], and a more recent study in [13].

\subsubsection{Services and revenues}

Demand modeling is based on penetration estimates for different technology subscribers in selected segments and their forecasted usage patterns. End-user modeling gives the usage amounts for active users of each service, per each segment and each technology.

The first step in the end-user modeling is to build the user experience and behavior process for the provided services. Process includes everything related to what the user experiences while interacting with the service: pricing, usability, service penetration (for person-to-person services), network performance, and the actual usage, e.g. listening the piece of music. Process includes also behaviors like reattempts and waiting times. 
Fig. 2 Technology rollout schedules (population coverage)

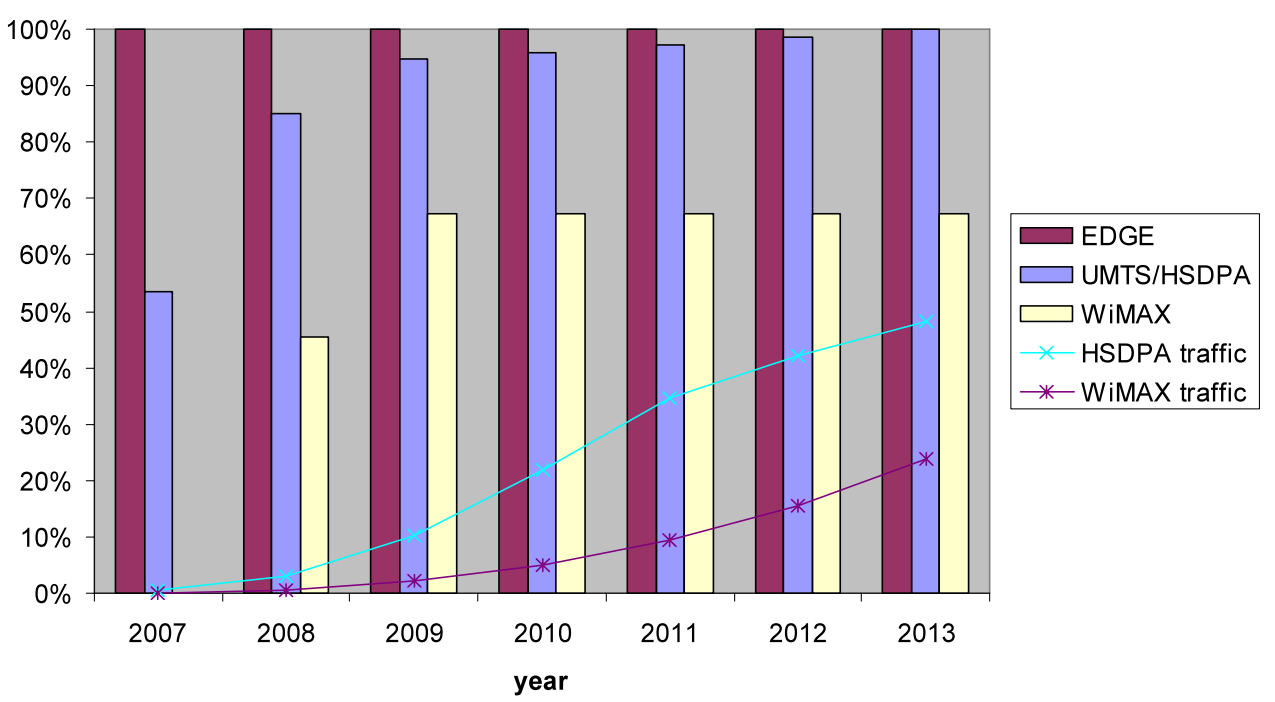

The parameters relating to the user experience differ by technology and user segment. The most important differences between technologies are: Network blocking/unavailability, Technical trouble or delay, Practical upstream bit rate, Practical downstream bit rate and Perceived quality of the service channel (differs especially for high capacity requiring services, like video call or streaming). All the above parameters are clearly better for the advanced technologies UMTS and WiMAX compared to the lower level technologies EDGE and especially GPRS. The differences between user segments include their valuation between time and money and their capabilities to use the services. The applied tariffs and tariff erosion are same to all technologies (presented in the Table 2).

The role of the end-user model is to create a link between service usage and user experiences with different technologies, user segments, and services. The reference parameter values used to calibrate the initial usage amounts with the set tariff levels are chosen between the advanced technology values and EDGE parameter values. Based on the parameters the end-user model calculates the benefit, cost, and success figures for each technology, service, and user segment, and for the reference. The actual paid tariff is part of the costs, which include also the so-called opportunity cost due to loss of available alternative benefits. Valuation of opportunity cost takes into account also the value of time, which differs between the four segments used in the modeling.

The service usage for technologies, user segments, and services are calculated using the end-user model by comparing the benefit, cost, and success figures with the reference. As the parameter values get better along with the advanced technologies the usage grows from the reference values, and respectively in case of lower level technologies the usage diminishes as the user expectations are not met. For more about the utilized end-user model, see Deliverable 19, Ap- pendix A, in [4]. Generally about end-user benefit analysis relating to mobile services, see [14].

Upon the usage figures we have applied the market size and market share of the operator, technology penetrations, and rollout schedules, to get the user amounts. As the Enduser model gives the usage volumes for active users of each service in each segment and technology, we have in addition estimated the penetrations of active users of each service type in each segment and technology.

Estimated percentages of different technology subscribers are based on terminal/handset penetrations. When the population coverage is incomplete, the potential usage and traffic amounts realize only partially according to the available coverage. The figures are dependent on the particular network operator and service operator provisioning. The population coverage development by the Network Operator was presented in Fig. 2. It should be noted that e.g. EDGE penetration is tracked here as for operator who provides EDGE network, not as general EDGE penetration. It is foreseen that if the operator goes for UMTS its data subscriber base is quite fast migrated from EDGE to UMTS, boosted by subscription packages including terminals and related terminal subsidies. WiMAX is in a weaker position to reach mass penetration in the W-E mobile market due to the path dependency of the dominant players and the benefit of scale in handsets, but has its possibility in the more niche market of special IP centric approach. The penetrations for users of different technologies are presented in Fig. 3. Those data users not having any of the presented technologies are supposed to use GPRS.

Subscribers utilizing more advanced technologies are supposed to have also the less advanced technologies in use. WiMAX penetration is estimated to be clearly lower than UMTS, due to the terminal availability, form and price factors. Potential laptop users e.g. are considered to be much lower in number than pocket size handset users. 
Fig. 3 Potential users of different technologies

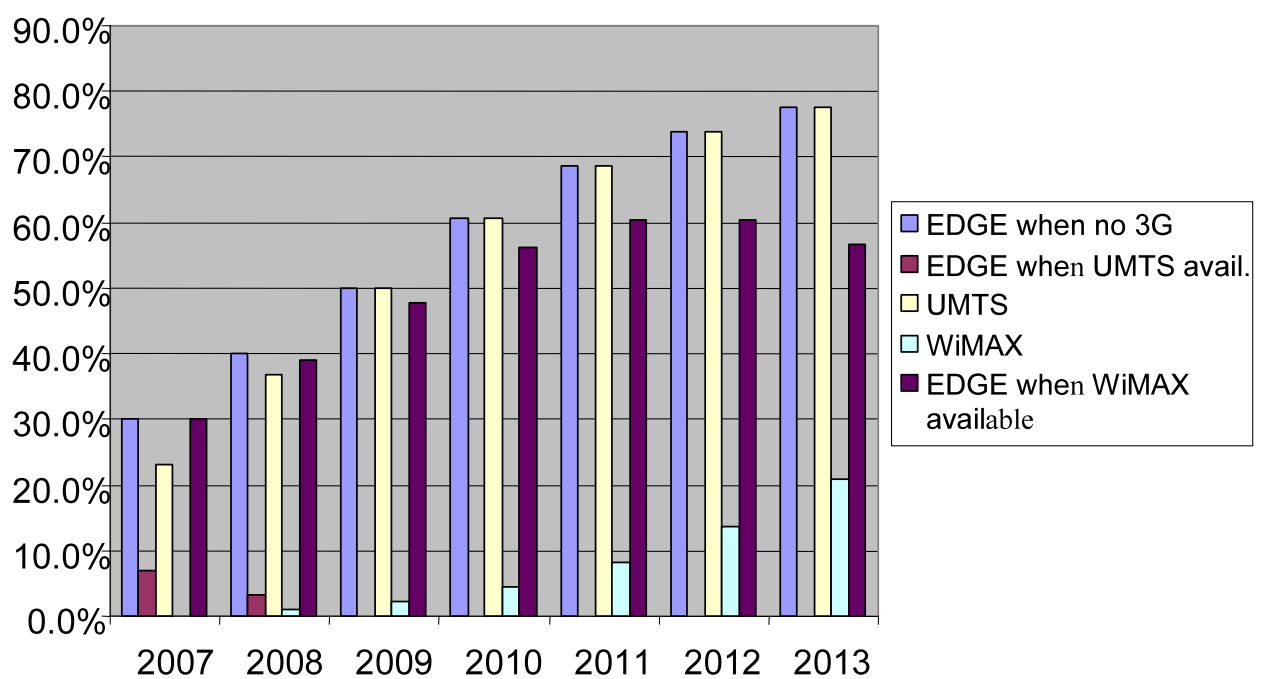

The customer base is supposed to be 16.5 million in the year 2007 , comprising a $30 \%$ market share of mobile users from the total population of 65 million. The penetrations of active users are out of this user base. Voice and SMS services are supposed to have $100 \%$ penetrations in all segments. Each technology induces slightly different penetrations for data services, so that higher capacity technology imposes more users, but this increase is not as significant as the usage amount difference calculated in the End-user model.

The Service Operator's revenues are calculated by combining the technology related user behavior from End-user model (usage amounts for the selected price level), with segment sizes and related actual active service users. The earlier the enhanced technology is deployed, the more traffic is generated, but only in the limits of general demand development and terminal availability. The generated average revenue per user (ARPU) is clearly higher for the more advanced technologies. On the other hand, also the costs are higher for early capacity deployment.

The Network Operator's revenues are based on the traffic amounts calculated in the Service Operator model. The wholesale tariff levels are defined so that the operating profits of the Service Operator and Network Operator are at the same level in the UMTS case. Same wholesale tariffs are applied for all cases.

Wholesale prices that the Service Operator pays to the Network Operator in the year 2006 are as follows, with $15 \%$ yearly price reduction applied thereafter:

- Narrowband conversational (voice): $0.011 € / \mathrm{min}$ (inbound and outbound)

- Wideband conversational (video telephony): $0.043 € / \mathrm{min}$ (inbound and outbound)

- Data: $0.15 € / \mathrm{MB}$ (both directions)
The annual price reduction is quite substantial compared to the average tariff erosion in the recent years, but is in accordance with the high increase of traffic foreseen, anyhow causing the Network Operator revenues to grow. At this phase the wholesale data traffic pricing is not differentiated between e.g. streaming, interactive, or background traffic classes.

\subsubsection{Results and conclusions}

Five sub-scenarios will be presented: "UMTS with HSDPA plus EDGE deployment" "UMTS plus EDGE deployment", "UMTS without EDGE deployment", "WiMAX plus EDGE deployment", and "WiMAX without EDGE deployment". For the NPV (net present value) calculations, discounts rate is $15 \%$, due to the fact that in the turbulent markets and heavy technology competition the future revenues from the investments are somewhat unsure. With reasonably high discounts rate, the possibly positive results are more dependable. The presented NPV does not include investments done before 2006 and potential positive cash flows after 2013, so it should be interpreted more like discounted cash balance over the years 2006-2013, but a slight rest value of the equipment is included.

In the UMTS cases, Service Operator's net cash flow increases towards the end of the study period. For the Mobile WiMAX cases, such growth is not seen, and the end results are more modest, although the cash flow keeps clearly positive. This is mainly due to UMTS being more mature technology (handsets and network) in the beginning, being able to serve all types of services.

From the cash flow results of the model, we can see that the revenues from the advanced services grow steadily in the UMTS case, as the demand and usage increase faster than the tariffs are falling, especially in the middle period. The results are improving also because the costs are leveling off 


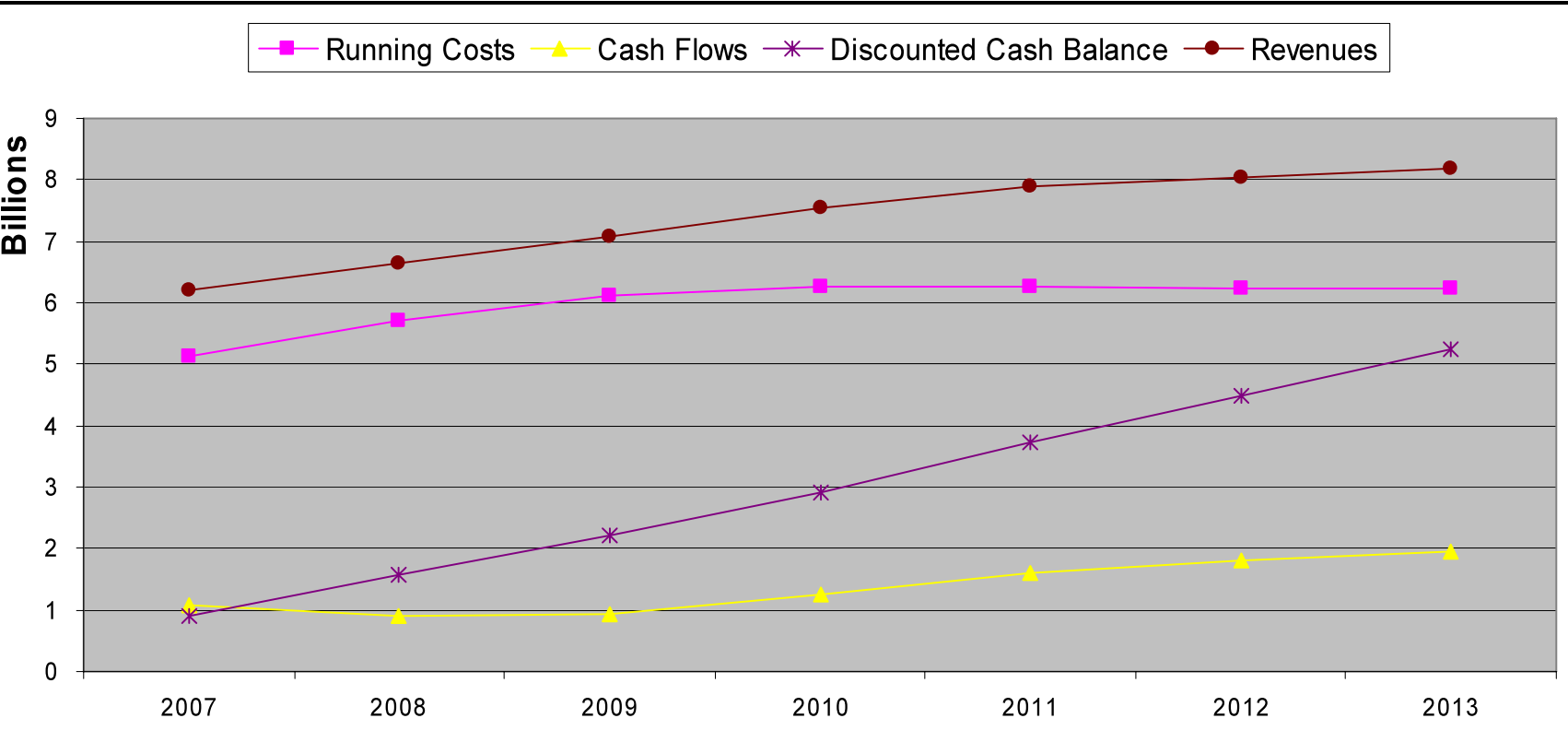

Fig. 4 Cash flows of the Service Operator (UMTS + HSPA)

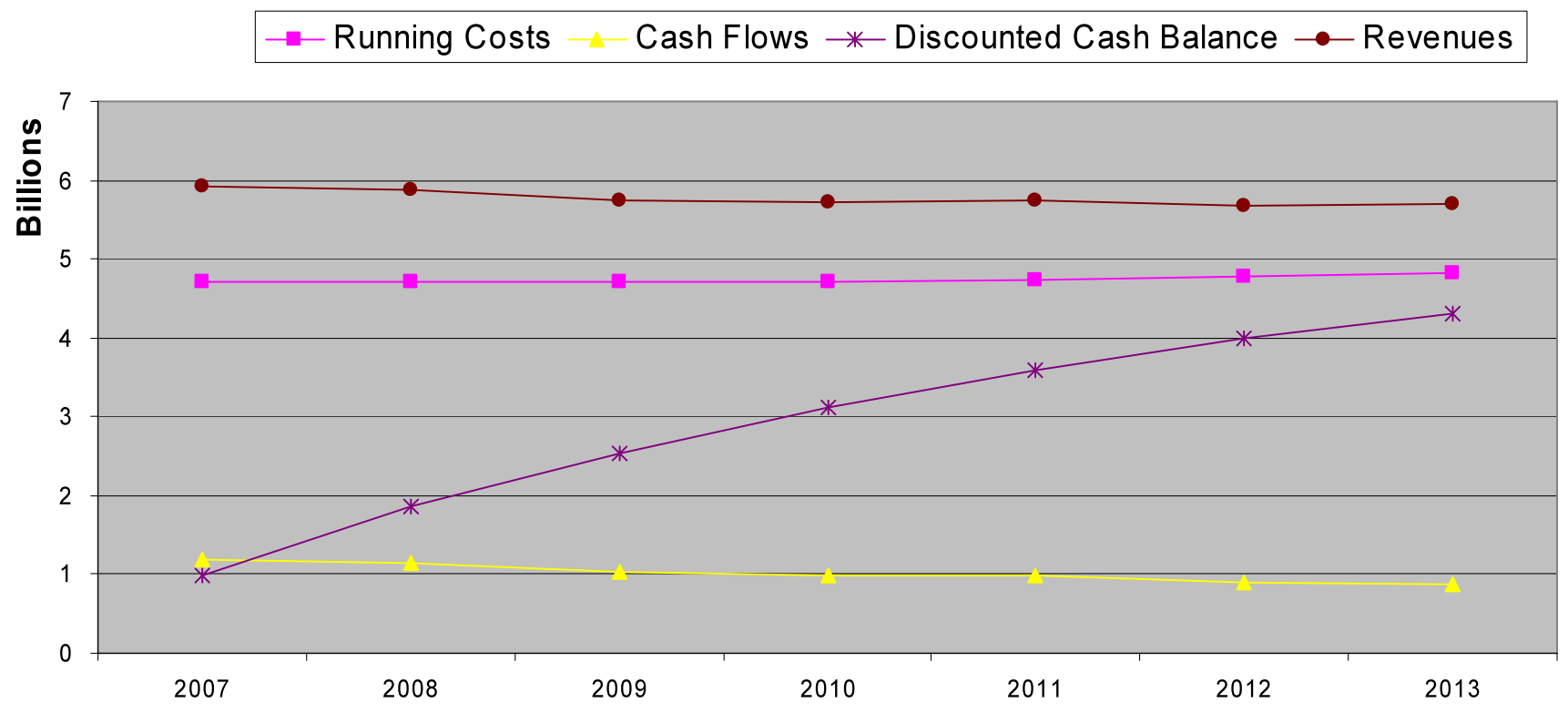

Fig. 5 Cash flows of the Service Operator (WiMAX)

towards the end of the study period. For the WiMAX case, the revenues do not grow to such level, because of lower amount of acquired high capacity users. See Figs. 4 and 5 below.

The Network Operator, on the other hand, has negative cash balance for all cases in the beginning, but then in two years the discounted cash balance turns to steady growth. Due to the negative cash balance in the beginning Network Operator's technology risk is higher compared to the Service Operator, who does not have to make so big investments. In the UMTS case, the Service Operator part- ner can catch more advanced data users, so that the traffic and thus revenues are estimated to grow higher also for the Network Operator providing UMTS. The investments or operational costs do not show crucial differences between the technologies. However, because of less traffic and thus revenues the payback for the WiMAX investment is not so strong in this kind of operator case. Cash flows of UMTS and WiMAX cases are presented below in the Figs. 6 and 7.

According to the results shown in the Table 7 below, it seems that successful competition is possible also by uti- 


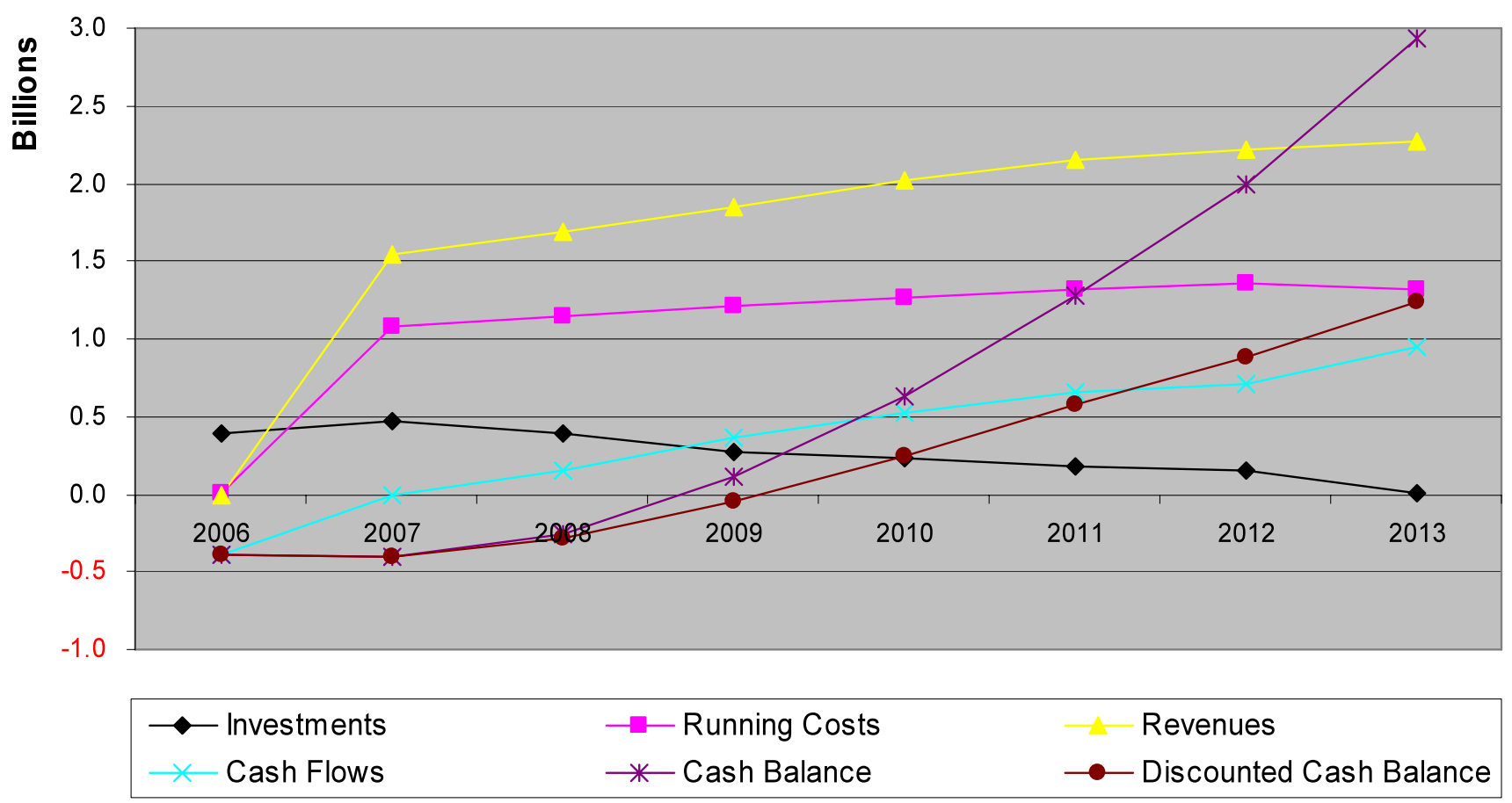

Fig. 6 Cash flows of the Network Operator (UMTS + HSPA)
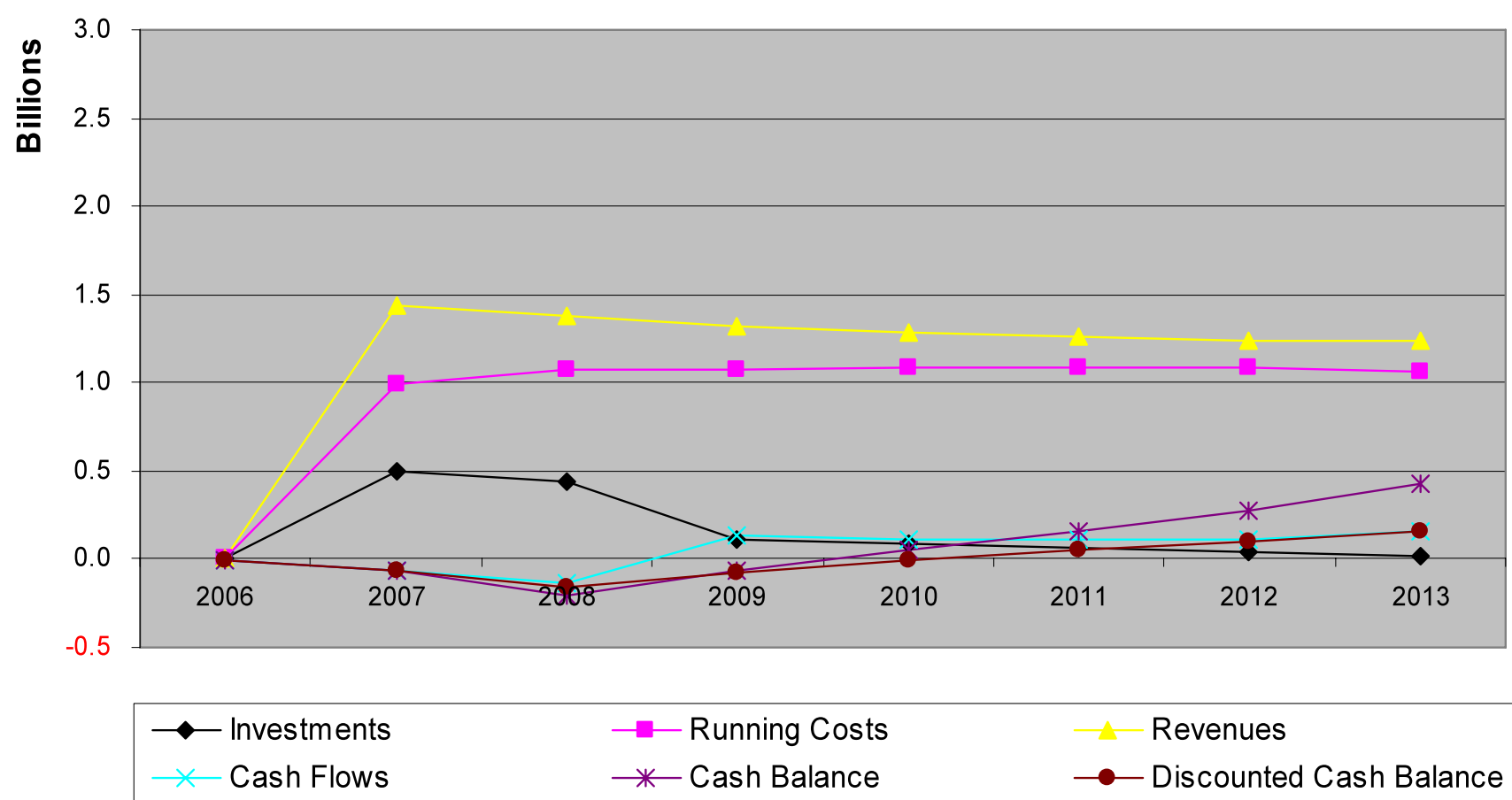

Revenues

- Discounted Cash Balance

Fig. 7 Cash flows of the Network Operator (WiMAX)

lizing another $3 \mathrm{G}$ technology, when the UMTS license is not available. The results for Mobile WiMAX are somewhat lower than for UMTS, but the license costs (which are not included here), might be lower for the other technology.
However, there are still uncertainties relating to the dissemination of technologies, which are not yet in mature mass production phase-either for the network part, or especially for the terminal/handset part. 


\begin{tabular}{|c|c|c|c|c|c|c|c|}
\hline $\begin{array}{l}\text { Technology } \\
\text { deployment }\end{array}$ & Unit & $\begin{array}{l}\text { NtwOper. } \\
\text { CAPEX }^{\mathrm{a}}\end{array}$ & $\begin{array}{l}\text { NtwOper. } \\
\text { OPEX }^{\mathrm{a}}\end{array}$ & NtwOper. NPV & $\begin{array}{l}\text { ServOper. } \\
\text { CAPEX }^{\mathrm{a}}\end{array}$ & $\begin{array}{l}\text { ServOper. } \\
\text { OPEX }^{\mathrm{a}}\end{array}$ & $\begin{array}{l}\text { ServOper. } \\
\text { NPV }\end{array}$ \\
\hline $\begin{array}{l}\text { UMTS/HSDPA } \\
\text { with EDGE }\end{array}$ & $\mathrm{B} €$ & 1.57 & 5.08 & 1.47 & 0.140 & 24.5 & 5.24 \\
\hline $\begin{array}{l}\text { UMTS with } \\
\text { EDGE }\end{array}$ & $\mathrm{B} €$ & 1.75 & 5.24 & 1.23 & 0.140 & 24.5 & 5.24 \\
\hline $\begin{array}{l}\text { UMTS without } \\
\text { EDGE }\end{array}$ & $\mathrm{B} €$ & 2.46 & 5.48 & 0.310 & 0.140 & 24.5 & 5.10 \\
\hline $\begin{array}{l}\text { WiMAX with } \\
\text { EDGE }\end{array}$ & $\mathrm{B} €$ & 0.919 & 4.40 & 0.330 & 0.103 & 19.7 & 4.32 \\
\hline $\begin{array}{l}\text { WiMAX } \\
\text { without EDGE }\end{array}$ & $\mathrm{B} €$ & 1.88 & 5.40 & -1.88 & 0.103 & 19.2 & 3.02 \\
\hline
\end{tabular}

${ }^{\text {a }}$ Discounted values, from year 2006 to 2013

This increases the risks for Mobile WiMAX cases related to the potential delay in market maturity. For the HSDPA, the future concerning the terminal and network technology availability and maturity is already more assured.

Plain EDGE deployment does not give optimal results due to lack of appeal to growing number of heavy data users, but is best as an auxiliary solution together with UMTS or WiMAX. The auxiliary EDGE deployment has clearly higher effect on the Network Operator business than on the Service Operator. This reflects that the investment savings are considerable. For the $2 \mathrm{G}$ business player going for Mobile WiMAX as 3G technology, the intermediate EDGE deployment is crucial, so that without it the NO WiMAX case becomes heavily negative. These findings relate to the fact that EDGE is deployed in the beginning of the study period, and if the EDGE is not deployed, more low capacity GPRS base stations have to be rolled out, raising the costs dramatically in WiMAX case. As the UMTS rollout is one year earlier, the effect is not so strong.

The revenue potential from UMTS and Mobile WiMAX relate to the End-user modeling results indicating that the growing revenues of especially business segment can only be captured with the higher-level technologies. HSDPA has been modeled here only as cost saving factor, as the data capacity per base station is increased, but it will probably also have some impact as to increase spending.

Especially the Network Operator part in the Mobile WiMAX alternative is in weaker position as looking the results, and also the risks are at the highest there, as the user base growth is delayed compared to the UMTS path. For this reason, it is natural that the WiMAX NO tries to raise the wholesale tariff levels. This would respectively cause some reduction in the profitability of the WiMAX Service Operator.

In this scenario a high market share has been assumed as for an incumbent player. For a new entrant to W-E mar- ket without $2 \mathrm{G}$ network the situation is more challenging, as we can see also from the two other scenarios presented in this paper. It would be possible to act as an MVNO in the $2 \mathrm{G}$ market, and build only the $3 \mathrm{G}$ IP overlay with Mobile WiMAX. In this case too the challenge is to get customer base large enough to compete with UMTS-economies of scale work for the UMTS players' benefit in the W-E market. As the challenge is more in the network provider side, one possibility for the WiMAX NO could be to try to find several MVNOs to sell their IP based services (including VoIP) operating on the deployed WiMAX network.

\section{2 $2 \mathrm{G}$ and $3 \mathrm{G}$ Service Provider/MVNO case}

For a new entrant not having a license to build own network, or not willing to take the investment risks, the Service Provider/Mobile Virtual Network Operator (SP/MVNO) approach provides an alternative business model. Here, the crucial factor is the relationship and contract terms with the incumbent network operator.

The SP/MVNO business case can be analyzed from many viewpoints. One interesting option would be to study the feasibility of different types of MVNO strategies (e.g. cost leadership vs. service leadership) for players with different backgrounds (e.g. fixed line operators, retailers, media houses). The quantitative nature of ECOSYS methodology and tool, however, is better suited for studies with emphasis on the cost (OPEX/CAPEX) and revenue structure of different technology options. In this study, the differences between two most commonly used virtual operator business models are analyzed, including a SP scenario and a MVNO scenario.

Becoming an SP/MVNO is a possible strategy for operators with many different backgrounds, e.g.:

1. Operator with $2 \mathrm{G}$ license and without $3 \mathrm{G}$ license $(\gg 3 \mathrm{G}$ SP/MVNO) 
Table 8 Summary of differences between the SP and MVNO model

\begin{tabular}{lll}
\hline$\#$ & SP model & MVNO model \\
\hline 1 & $\begin{array}{l}\text { Network operator's identity } \\
\text { Changing of network generally requires changing SIM } \\
\text { cards, transferring prepaid subscription from one network } \\
\text { to another is not possible }\end{array}$ & $\begin{array}{l}\text { Own network identity (MNC, IMSI) } \\
\text { Can route to other network, when required, without } \\
\text { changing SIM cards regardless of subscription type }\end{array}$ \\
$\begin{array}{l}\text { Network operator's interconnection agreements } \\
\text { Services are based on services provided by the network } \\
\text { operator, development of own services is very limited }\end{array}$ & $\begin{array}{l}\text { Own interconnection agreements } \\
\text { Incoming traffic to the network is priced according to the } \\
\text { pricing of the network operator }\end{array}$ & $\begin{array}{l}\text { Possibility to create value-added services (i.e. mobile } \\
\text { switchboard, short numbers etc.) }\end{array}$ \\
$\begin{array}{l}\text { Services are priced according to the pricing offered by the } \\
\text { network operator }\end{array}$ & $\begin{array}{l}\text { Incoming traffic to the network is priced by operator itself } \\
\text { Service operator from number portability viewpoint } \\
\text { Network and value-added service elements of the network } \\
\text { operator, it is not possible to have own value-added service } \\
\text { elements } \\
\text { Turnover comprises traffic invoicing }\end{array}$ & Services are priced component-specifically \\
& & $\begin{array}{l}\text { Network operator from number portability viewpoint } \\
\text { Own network elements MSC, HLR, SRR, IN as well as } \\
\text { value-added elements if it so wishes }\end{array}$ \\
& &
\end{tabular}

Table 9 Wholesale tariffs

\begin{tabular}{lll}
\hline Service & SP model & MVNO model \\
\hline Voice calls (originating) & $35 \%$ of retail price & $35 \%$ of retail price \\
Voice calls (terminating) & 0 & $35 \%$ of retail price \\
Video calls (originating) & $35 \%$ of retail price & $35 \%$ of retail price \\
Video calls (terminating) & 0 & $35 \%$ of retail price \\
Other services (originating) & $35 \%$ of retail price & $35 \%$ of retail price \\
Other services (terminating) & 0 & 0 \\
\hline
\end{tabular}

2. Operator with $3 \mathrm{G}$ license but without $2 \mathrm{G}$ license $(\gg 2 \mathrm{G}$ SP/MVNO)

3. New entrant without any licenses (2G/3G SP/MVNO)

4. Operator acting as an Mobile Network Operator in some geographical markets and as an SP/MVNO in another.

In this study, the third case is assumed, i.e. the operator is assumed to have no spectrum licenses in any markets.

The study concentrates on building a flexible model for comparing the investment levels, cost structures, and revenue streams between the SP and MVNO scenarios. The model can be used to gain insight to the tradeoffs between costs and revenues when deciding on the most suitable level of outsourcing. Furthermore, by comparing the results of this study to the other scenarios, the general feasibility of both SP and MVNO models can be assessed. The main differences between SP and MVNO model are presented in the Table 8 [17].

An incumbent operator with GSM, EDGE, and UMTS network (see Scenario 1) has been assumed to be contracted with for the network capacity required for the services. The two models are very different in terms of investment struc- tures. In the SP model the costs are mainly OPEX as most of the network equipment and service machinery is outsourced to the network operator. In the MVNO model, the level of outsourcing is lower and CAPEX is higher due to investments to own switching center, gateways, messaging centers, etc. However, bulk of the investments is in the network operator side.

Most of the costs of a SP/MVNO are OPEX, from which a significant part of consists of the outsourcing of the network infrastructure. In the case of SP, these costs are higher, as a result of higher degree of outsourcing. The pricing of the outsourced services is usually negotiated between the SP/MVNO and the network operator on a commercial basis, without regulator intervention. Generally, the wholesale price level can be assumed to be somewhere between the network operator's cost of providing the network services and the retail prices. As the contracts can be freely negotiated, there are many options and possible revenue sharing models that could be applied. The negotiated wholesale tariffs with the network operator that are assumed for SP and MVNO are presented in the Table 9. For reference studies and market data relied, see [15-17] and [18]. 


\subsubsection{Results and conclusions}

The MVNO business case proves to be significantly more profitable. An obvious reason for the differences lie in the MVNO's higher revenues that more than compensate the higher initial investment and paid termination fees. This is illustrated in Fig. 8, which shows the differences in the revenues and cost structures between SP and MVNO models. The Network Operator's share of revenue dominates the OPEX in both scenarios, but is even more strongly in the $\mathrm{SP}$ scenario. In the MVNO scenario, also the revenues are slightly higher due to net profit from termination fees. The differences relate to MVNO's more independent position than the SP's towards the Network Operator.

Although the initial investments make the cash flow dive deeper for the MVNO in the first-year, the higher margins raise the profitability to a higher level compared to the SP. The cost breakdowns highlight also the importance of OPEX in both the SP and the MVNO model. Sales and marketing related OPEX stays on approximately the same level throughout the study period, whereas customer case and billing slowly increases and takes over the S\&M costs in the late years.

Figure 9 shows the economic results for the SP and MVNO scenarios separately for Large and Nordic country

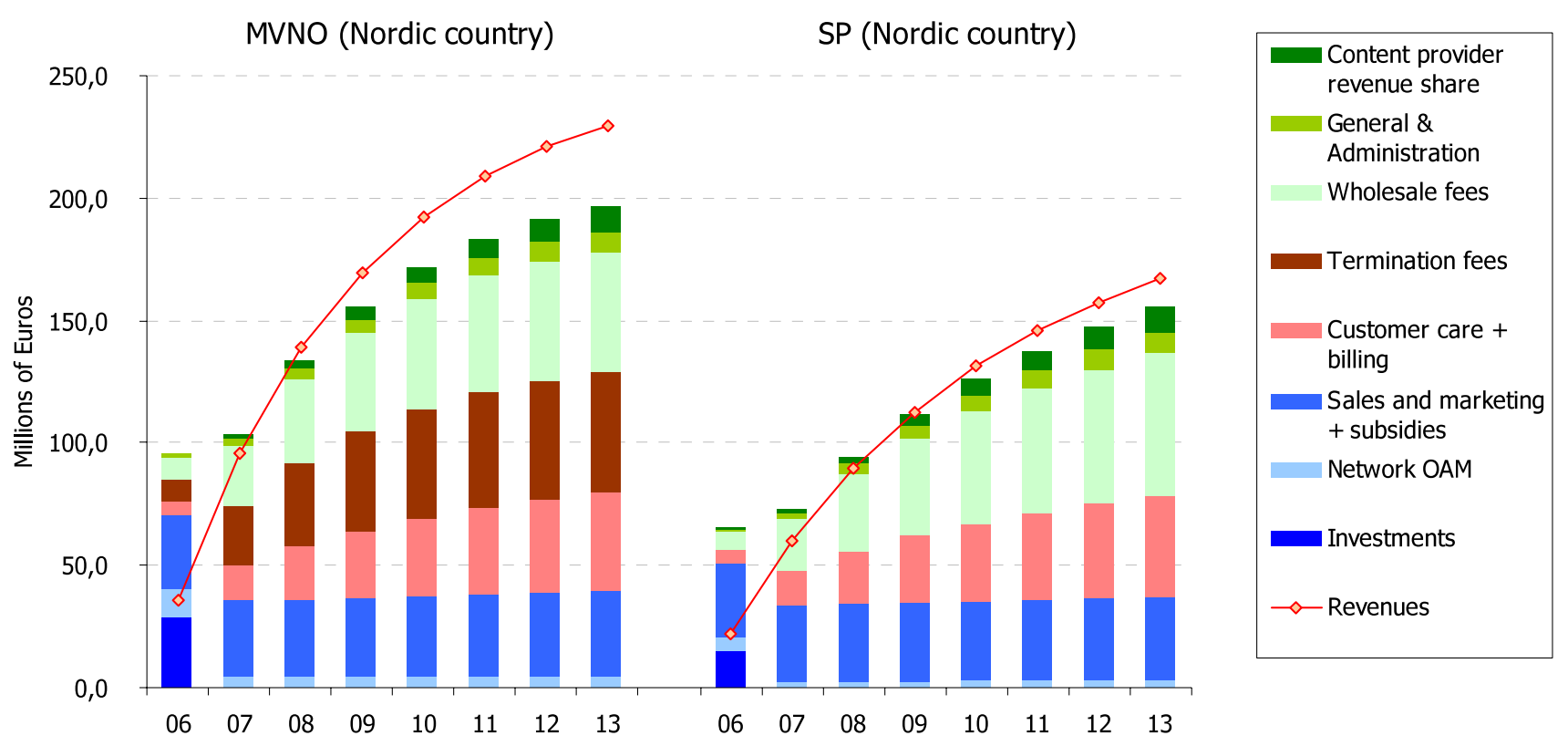

Fig. 8 Revenues and cost breakdowns for MVNO and SP scenarios
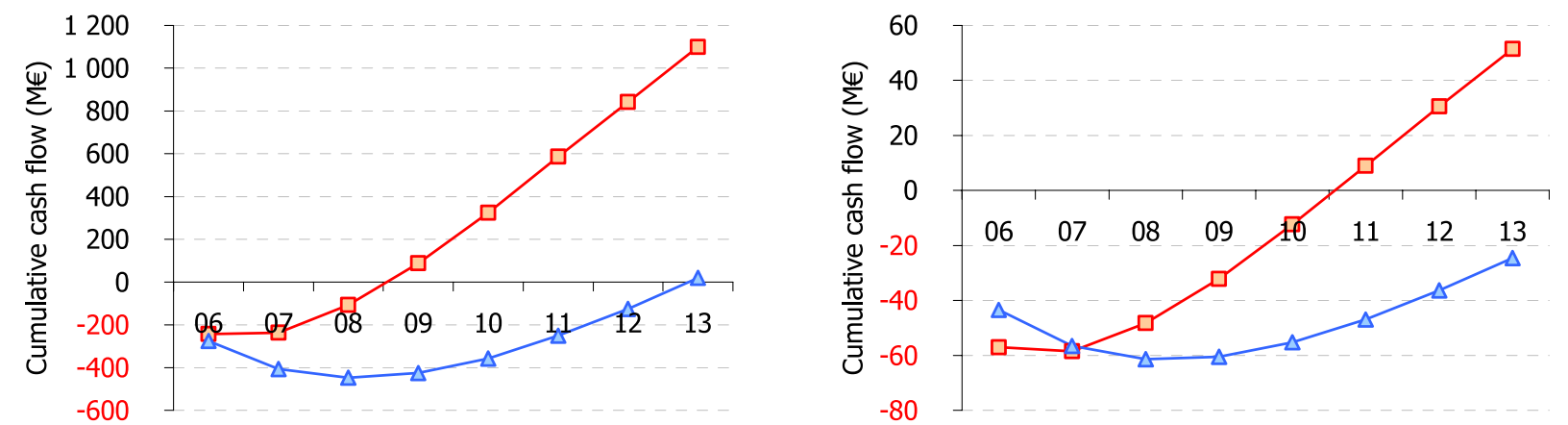

$\rightarrow \square$ Large_MVNO $\triangle-$ Large_SP

$\rightarrow \square$ Nordic_MVNO $\rightarrow-$ Nordic_SP

\begin{tabular}{|c|c|c|c|c|c|c|c|}
\hline Scenario & NPV (M€) & IRR & Payback (yrs) & Scenario & NPV (M€) & IRR & Payback (yrs) \\
\hline Large_MVNO & 401,3 & $49,2 \%$ & 3,5 & Nordic_MVNO & $-0,7$ & $14,6 \%$ & 5,6 \\
\hline Large_SP & $-178,6$ & $0,8 \%$ & 7,9 & Nordic_SP & $-36,3$ & $-9,0 \%$ & $>8$ \\
\hline
\end{tabular}

Fig. 9 Economic results for MVNO and SP scenarios 

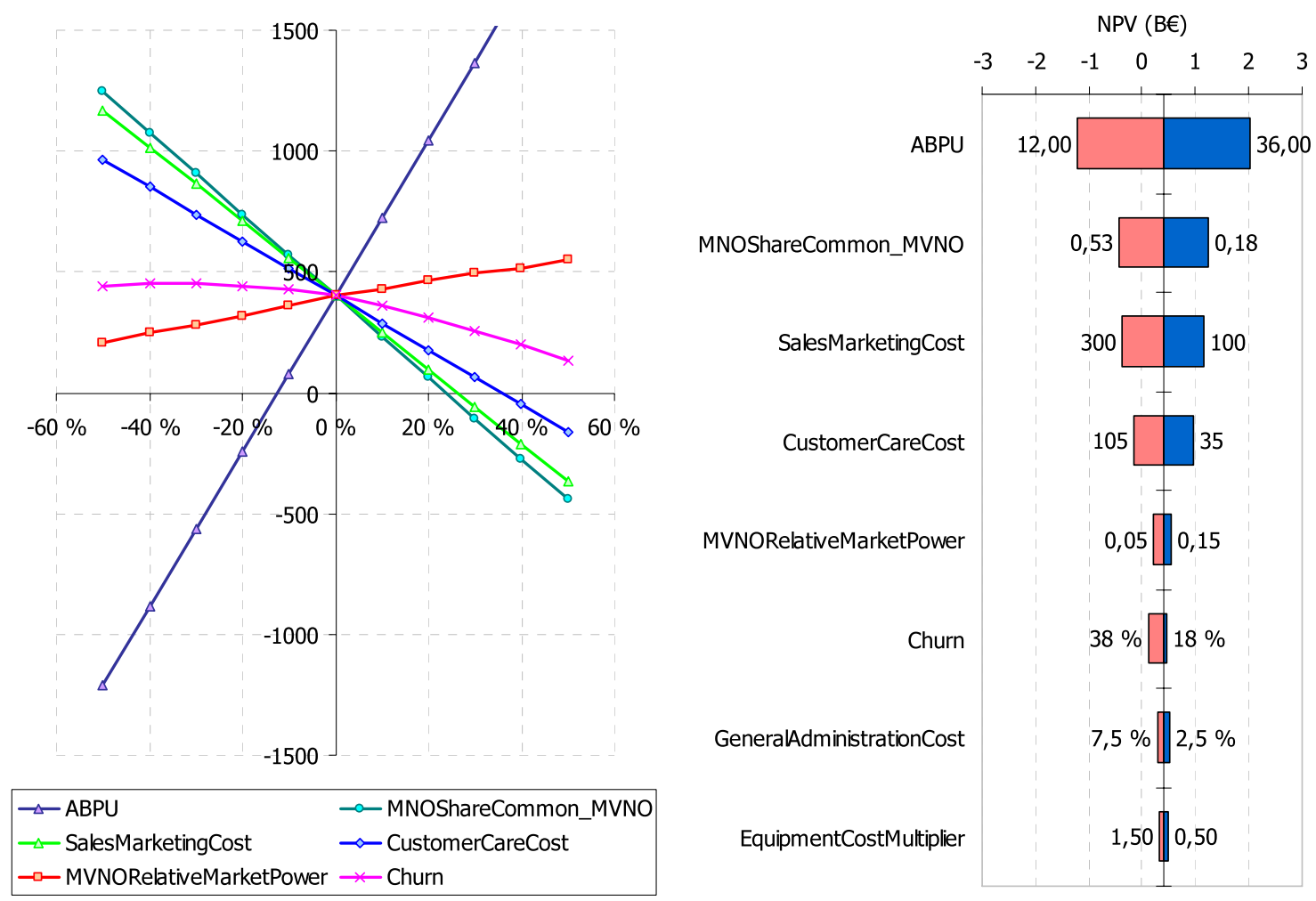

Fig. 10 Sensitivity analysis results, Large country/MVNO

types. The MVNO business case proves to be significantly more profitable in both country types. In the Large country, the MVNO scenario yields an NPV of over $400 \mathrm{M} €$ and the payback time is 3.5 years, whereas the SP scenario has negative NPV and a payback time of almost 8 years. In the Nordic country, the results are generally worse.

When comparing the results of the two country types, the Large country business cases prove to be more profitable due to better economies of scale and resulting lower unit costs. In both country types, however, OPEX outweighs CAPEX in cost breakdown and NPV sensitivity analysis. The most significant OPEX elements include the Average Billing Per User (ABPU), MNO's share of the revenue, sales \& marketing costs, and customer care costs. Market share evolution, churn level, and network OA\&M related costs are clearly less significant. In Figs. 10 and 11, we can see that about $13 \%$ reduction in ABPU can make even the Large country MVNO case NPV negative, but about $7 \%$ increase in ABPU, or $10 \%$ reduction in MNO's share of the revenue, can make the Large country SP case positive. For further discussion on sensitivity analysis results, please refer to the Deliverable 19 [4].

The contract terms and revenue sharing deal between the SP/MVNO and MNO are of prime importance when looking for a profitable business case. Based on the results of this study, the MNOs share of retail revenue should not be more than $30-40 \%$ in the MVNO case and $25-30 \%$ in the SP case.
Compared to the incumbent cases in previous scenarios, we can directly see that the revenue and profitability potential is limited. Only in the "Large" country type, clear positive results are indicated. These results are in line with the perception that only a few significant SPs or MVNOs are emerged and still in operation in the Nordic countries. New mobile services, Internet business models and regulatory intervention in the wholesale pricing are the foreseen possibilities to change the situation.

\subsection{CDMA450 case}

This scenario investigates the potential of CDMA2000 technology in $450 \mathrm{MHz}$ frequency band, also known as CDMA450. The studied case includes a Greenfield CDMA450 operator entering the Western-European market to compete with $2 \mathrm{G}$ and $3 \mathrm{G}$ mobile networks. The CDMA450 operator has acquired a license for the 450 -frequency band with the possibility to use up to three $1.25 \mathrm{MHz}$ carriers.

The operator enters a mature market in terms of communication facilities. There are already several GSM/GPRS and UMTS operators in the market. A fixed access operator owns and runs a fixed network infrastructure from which the newcomer will need to lease transport capacity. We assume that initially multi-mode terminals that enable roaming between CDMA450 and GSM/GPRS/W-CDMA networks are not available in the market. We study the economics for a 


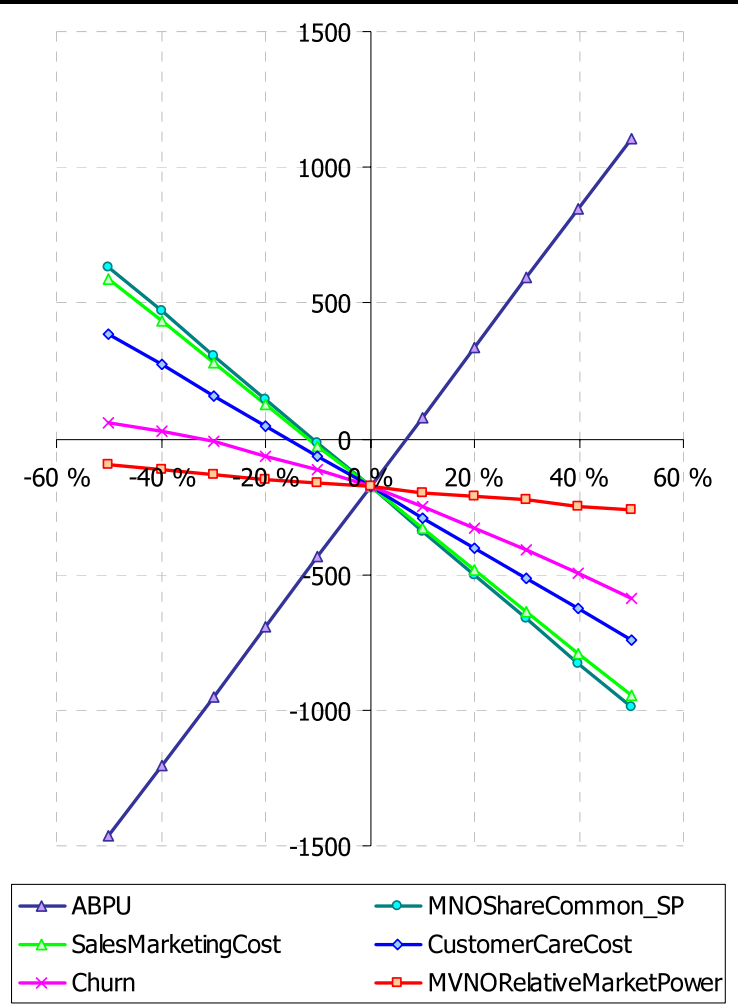

Fig. 11 Sensitivity analysis results, Large country/SP

combined Service and Network Operator with two build out strategies: CDMA450 covered in the whole country or just in rural areas. Study period is 2006-2011. Monthly average revenue per user (ARPU) is $€ 28,44$.

The network build out parameters are presented in the Sect. 3 Assumptions, in common with the Scenario 1. The new entrant operator aims to offer CDMA450 services throughout the country. The focus however is on rural areas, as the technology is intended to be used as an ADSL Light product offering data applications and VoIP services to the users. In the Nordic countries, where population in the rural areas is scattered and where it is very difficult to roll out DSL technology, CDMA450 would thus be a substitute. The mobility comes as an extra value to the users. The operator will support the customers throughout the country with CDMA450 coverage, and also the dense area roll-out is done fast, to support the customers possessing only CDMA450 terminals. For reference studies and market data see $[19,20]$ and [21].

\subsubsection{Results and conclusions}

The main economics results are given in Fig. 12. The presented results are obtained assuming Discount Rate of $15 \%$. Presented values IRR and NPV are values before tax reduction.

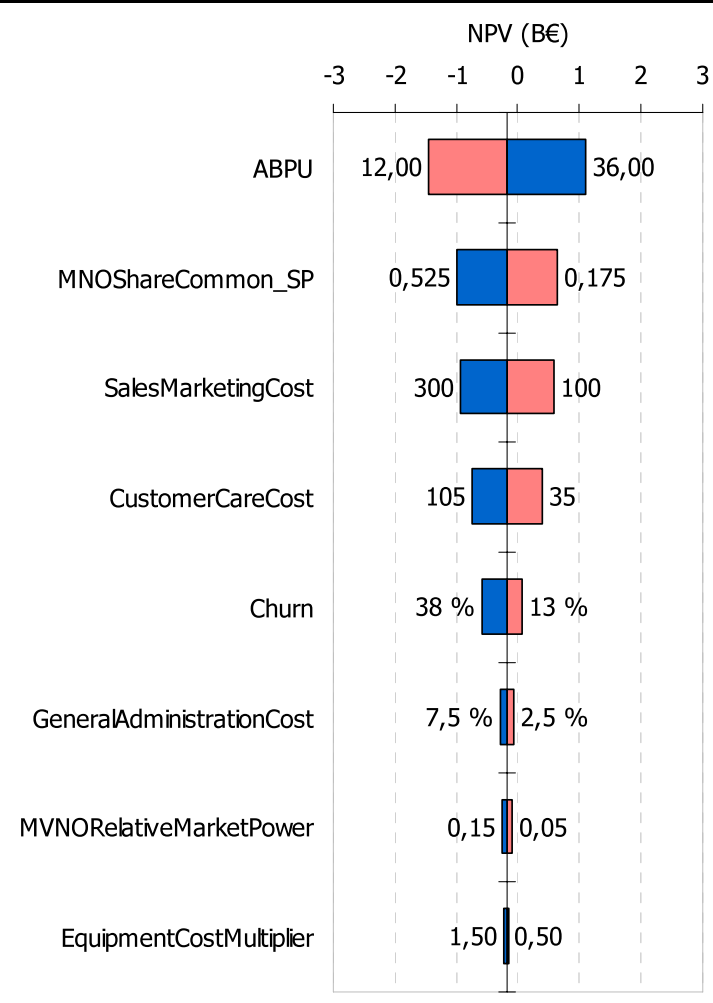

Results show that new entrant building CDMA450 network is not a competitive in small Western European countries due to rather high investments and low customer base. On the other hand the case could give a pay back ( 5 years) in large country where customer base is much higher. As seen, the NPV is positive for the large country cases both for the full country coverage and rural area coverage. The best case is the rural large country case. In this case the large coverage of each base station is one of the assets for CDMA450. However the market share is very uncertain and all cases involve high risks due to the network investments. From Fig. 12 we can notice that especially in the "Large country with total coverage" case the accumulated cash flow goes quite deep with the network investments. Altering the customer base will alter the profitability considerably. This means also that the business player has to have a deep enough capital base for the operation.

These results are quite much in line with the conclusions from the Scenario 2: in a Nordic type of small population, sparsely populated country the entry to the market is challenging. Even though this scenario indicates positive results from the Large country type they are very risky and the pay back time rather long. For that reason the Large country MVNO case, with low investments, presents itself as more lucrative a choice. 
Fig. 12 CDMA450 business

case-main results
CDMA450 Case - Accumulated Cash Flow

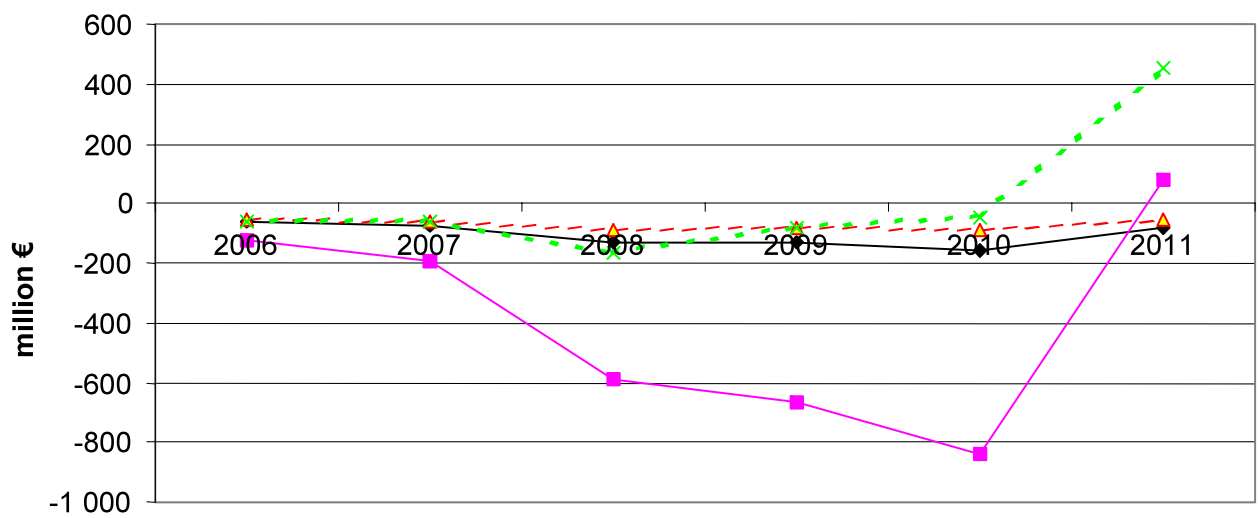

\begin{tabular}{|l|c|c|c|}
\hline \multicolumn{1}{|c}{} & \multicolumn{3}{c|}{- CDMA total - large } \\
\hline Scenario & NPV [million€] & IRR & $\begin{array}{c}\text { Payback } \\
\text { [years] }\end{array}$ \\
\hline CDMA total - small & -66 & $-3 \%$ & - \\
\hline CDMA total - large & 88 & $26 \%$ & 5 \\
\hline CDMA rural - small & -53 & $-8 \%$ & - \\
\hline CDMA rural - large & 424 & $62 \%$ & 5 \\
\hline
\end{tabular}

\section{Final remarks}

In this study, three mobile business scenarios have been evaluated, trying to analyze which are the economically viable solutions in the Western European context. New economic opportunities generated by emerging mobile technologies and service concepts have been identified and the profitability figures of various scenarios have been calculated.

Three scenarios for incumbents and new entrants have been defined - those having a UMTS license and those lacking it-leaving alternatives for new competing $3 \mathrm{G}$ technology deployment or acting as a MVNO without own radio infrastructure. Most of these scenarios have been analyzed in two country groups that are not exactly representative of any defined country, but rather share typical demographic characteristics.

According to the cases investigated, the incumbent operators are the players with the strongest position. The UMTS path as continuum for the prevailing GSM technology in Europe is the optimal approach for those who have the UMTS license-for which they have paid a high price. Although most European incumbents have purchased the license, also those building on competing WiMAX technology can reach a viable position. An intermediate technology, like EDGE, having already now a good terminal penetration is anyway needed for economically sound business case.

One possibility for a Network Operator having a lower market share is to provide capacity for virtual service providers to increase the served customer base and traffic.
The modeling results demonstrate that even in the competitive market there are enough margins for beneficial cooperation between Network Operator and Service Operators, if the total advanced user base served by the Network Operator is big enough. Service Operator is not so dependent on the size of its user base, due to lower fixed investments.

There is some space for the newcomers to maneuver but the revenue potential is slighter and risks are higher. Especially for the Nordic type of country the new entrant business case is very challenging, due to the narrow customer base and scattered population. Both virtual operator and network-based approaches are vulnerable according to the Scenarios 2 and 3.

Nevertheless, though smaller scale start within the study period, the emergent players might build foothold for the new era of Internet based service business through ubiquitous mobile access. This business is still biding its time, but might completely change the telecom and electronic media market. However, its effects cannot yet be projected to the study period of 2007-2013.

This study paves the way for comprehensive technoeconomic modeling needed in the more and more complicated environment of telecom business. This analysis uniquely links three modeling approaches dynamically together; namely the Network Operator cost modeling, the Service Operator's service, revenue and operational expenditure modeling, and the end-user benefit and behavior modeling. Different technology and business choices can thus be compared for the optimal solution. 
Acknowledgements The authors would like to acknowledge the support from the EUREKA CELTIC program, and the colleagues in the ECOSYS project.

\section{References}

1. Monath, T., et al. (2003). Economics of fixed broadband access network strategies. IEEE Communications Magazine, 41, 132139.

2. Katsianis, D., et al. (2001). The financial perspective of the mobile networks in Europe. IEEE Personal Communications, 8, 58-64.

3. Ims, L. (1998). Broadband access networks introduction strategies and techno-economic evaluation. London: Chapman \& Hall.

4. ECOSYS project web site: http://optcomm.di.uoa.gr/ecosys/ deliverableslist.html.

5. Varoutas, D., et al. (2003). Business opportunities through UMTSWLAN networks. Annals of Telecommunications, 58, 553-575.

6. Harno, J. (2002). 3G business case successfulness within the constraints set by competition, regulation and alternative technologies. The Journal of the Communications Network, 1(2), 159-165.

7. Harno, J. (2005). With or without UMTS license-can network deployment with alternative technologies compete with UMTS in Europe? The Journal of the Communications Network, 4(3), 147152.

8. Olsen, B. T., et al. (2006). Technoeconomic evaluation of the major telecommunication investment options for European players. In IEEE network, July/August 2006.

9. WiMAX Forum, website: http://www.wimaxforum.org/.

10. Global mobile Suppliers Association, GSA website: http://www. gsacom.com/.

11. Olsen, B. T., et al. (1996). Technoeconomic evaluation of narrowband and broadband access network alternatives and evolution scenario assessment. IEEE Journal on Selected Areas in Communications, 14(8).

12. Johansson, K. (2005). Cost efficient provisioning of wireless access. Licentiate thesis, Royal Institute of Technology.

13. Johansson, K., Zander, J., \& Furuskar, A. (2007). Cost efficient deployment of heterogeneous wireless access networks. In Proc. IEEE vehicular technology conference VTC2007.

14. Pohjola, O.-P., \& Kilkki, K. (2008). Value-based methodology to analyse communication services. In 5 th conference on telecommunications techno-economics (CTTE2006). Athens, Greece, June 2006. Available at http:/holistic.nokia.com.

15. Smura, T., Kiiski, A., \& Hämmäinen, H. (2006). Technoeconomic analysis of mobile virtual network operators: strategies, investments, and revenues. In 5th conference on telecommunications techno-economics (CTTE2006), Athens, 8-9 June 2006.

16. Katsianis, D., et al. $3 \mathrm{G}$ mobile virtual network operators (MVNOs): business strategies, regulation and policy issues. In S. Park (Ed.), Strategies and policies in digital convergence. Idea Group Publishing.

17. Saunalahti Group Oyj (2004). Capital Markets Day presentation 30.11.2004. Available at http://www.saunalahtigroup.fi/.

18. Telenor. (2004). Partner contracts. http://telenormobil.no/bedrift/ partnere/partneravtaler.do.

19. Samra, S. (2004). Worldwide success of CDMA2000: benefits to operators in $450 \mathrm{MHz}$. In CDMA450 evolution seminar. June 2004, Warsaw, Poland.

20. Albright, P. (2005). Revision of the vision. In Evolution. 01 November 2005. Available at http://www.telecoms.com/.

21. CDMA Development Group (CDG). (2005). Website. Available at http://www.cdg.org.

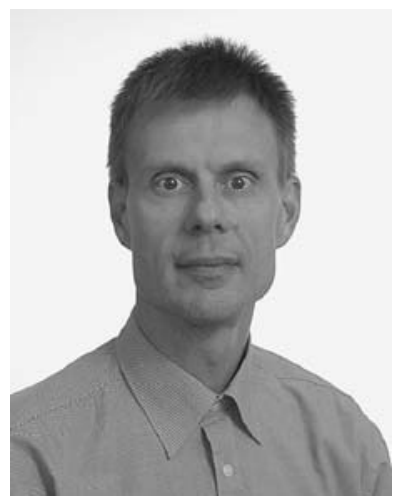

Jarmo Harno received his M.Sc. degree in Mathematical Analysis from the University of Helsinki in 1983. After working in SW industry he joined Nokia in 1987, and has worked as systems analyst and manager in R\&D, Quality Assurance and Product Management. He started as a senior research scientist on techno-economics with Nokia Research Center in 2001. As doing research on the future telecom technologies and service concepts, he has also taken part in the EU IST framework co-operation project TONIC (2001-2002) and EUREKA's CELTIC co-operation project ECOSYS (2004-2006). Mr. Harno is an author of several journal articles and conference presentations relating to techno-economics and telecom business modelling. He is also inventor for some patents relating to telecom technology and services.

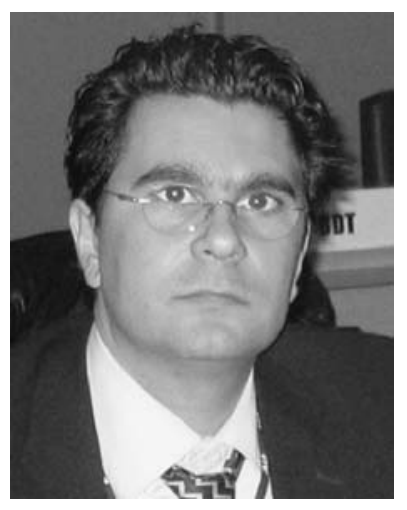

Dimitris Katsianis received the Informatics degree, the M.Sc. in Signal Processing and Computational Systems from and the Ph.D. diploma in network desing with techno-economics aspects from the University of Athens, Dept. of Informatics and Telecommunications. $\mathrm{He}$ is a research fellow with the Optical Communications Group, participating in several European $\mathrm{R} \& \mathrm{D}$ projects. He has worked as an expert scientific advisor with several firms in the field of technoeconomic \& network design studies including national activities for techno-economic evaluation of broadband strategies. His research interests include broadband communications and methodology of network design with techno-economic aspects. He has more than 50 publications in journals and conferences in the field of techno-economics and telecommunication network design and he serves as a reviewer in journals and conferences.

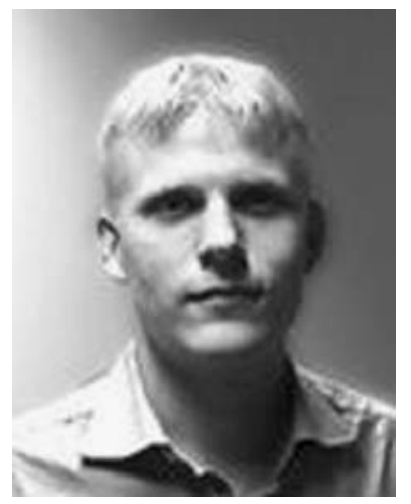

Timo Smura is a research scientist and a post-graduate student in the Department of Communications and Networking at the TKK Helsinki University of Technology. His research work has been published in a variety of journals, books, and conference proceedings. His research interests include emerging wireless technologies and services, technoeconomic modelling of mobile network investments, competition between technologies and standards in mobile communications, and mobile operator business models and strategies. 


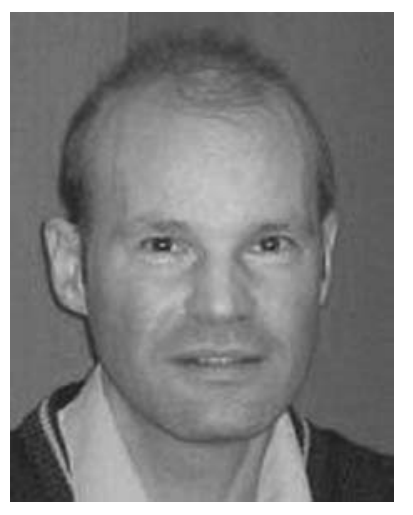

Thor Gunnar Eskedal received his M.Sc. degree in physics from the university of Oslo, Norway in 1990. After graduation he started working as a research assistant at the Norwegian institute of Technology (NTH) in Trondheim. In 1991 he received his business economics degree from BI Norwegian School of Management and joined Telenor R\&I. At Telenor he started working with system architecture, broadband technologies an IP network performance. Since 1998 he has been following standardisation and uptake of various wireless networks such a s 2G/3G and Wi-Fi. From 2006 his main focus has been on business modelling, techno-economic analysis and strategy of network technology usage and roll out.

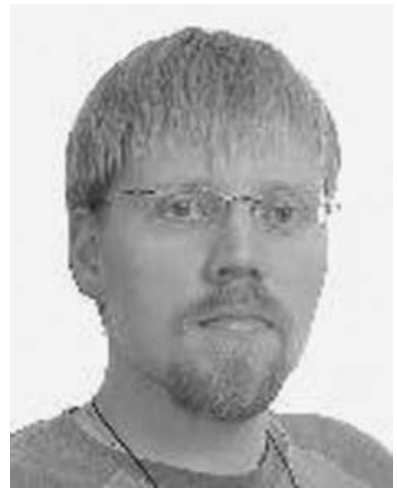

Olli Pekka Pohjola received a Master of Science in Technology with honours in Engineering Physics and Mathematics from Helsinki University of Technology in 1998. Since then he has worked with Nokia in various positions. He designed the first optical transport system for Nokia Networks and developed novel optical transport solutions in Nokia Research Center. He has developed a methodology to holistically model and analyse user experience, economic, and technology aspects of ecosystems. He was been commercializing the system with Nokia Networks. Currently Olli-Pekka is a researcher for Smart Spaces Laboratory at Nokia Research Center, Tampere, Finland, where his research focuses on the conceptual model and user interfaces for the Smart World.

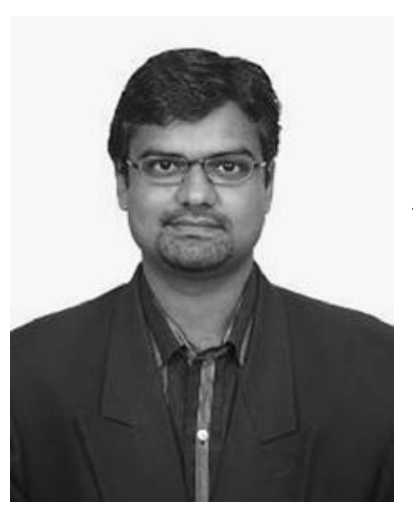

K.R. Renjish Kumar is a Ph.D. student at Helsinki University of Technology and Manager, TME Technology Services Lab, at Capgemini Consulting, India. Prior to joining Capgemini, he was with Networking Lab, Helsinki University of Technology as research scientist, working on techno-economic issues in mobile, convergence and international roaming. He was with Siemens ICM, Singapore as R \& D engineer, working on the policy server design prototype for UMTS core network and with Cognizant
Technology Solutions as Programmer Analyst. Renjish has a Masters (Computer science) from National University of Singapore (NUS) and B.E. (Electronics and communications) from National Institute of Technology (N.I.T.) Surathkal, India. He participated in CELTIC/EUREKA project ECOSYS, involving key players of the European telecom industry as team member and work package leader for Fixed-Mobile Convergence. Renjish has published over 20 papers in international conferences and journals on topics covering technology as well as business issues in telecom and Internet. His current areas of interest include techno-economic and strategic studies in the telecom, Internet and media sectors with a focus on systems, platforms and architectures. Renjish is a member of the IEEE.

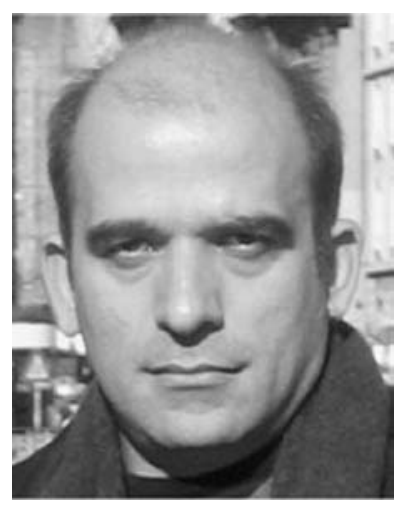

Dimitris Varoutas holds a Physics degree and M.Sc. and Ph.D. diplomas in communications and technoeconomics from the University of Athens. He is a lecturer on telecommunications techno-economics in the Department of Informatics and Telecommunications at the University of Athens. He has been participating in numerous European $\mathrm{R} \& \mathrm{D}$ projects in the RACE I \& II, ACTS, Telematics, RISI and IST frameworks in the areas of telecommunications and techno-economics. He actively participates in several techno-economic activities for telecommunications, networks and services such the ICT-OMEGA and the CELTIC/CINEMA projects, as well as the Conferences on Telecommunications TechnoEconomics. He also participates in or manages related national activities for technoeconomic evaluation of broadband strategies, telecommunications demand forecasting, price modelling etc. His research interests span design of optical and wireless communications systems to technoeconomic evaluation of network architectures and services. He has published more than 60 publications in refereed journals and conferences in the area of telecommunications, optoelectronics and technoeconomics, including leading IEEE Journals and conferences. He is a member of LEOS, Communications, Circuits and Systems, Education and Engineering Management Societies of IEEE and serves as reviewer in several including IEEE journals and conferences. 